\title{
Rate of Lineage Origin Explains the Diversity Anomaly in the World's Mangrove Vegetation
}

\author{
Robert E. Ricklefs, ${ }^{1, *}$ Andrea E. Schwarzbach, ${ }^{2, \dagger}$ and Susanne S. Renner ${ }^{1,3, *}$
}

1. Department of Biology, University of Missouri-St. Louis, St. Louis, Missouri 63121;

2. Department of Biological Sciences, University of Texas, Brownsville, Texas 78520;

3. Department of Biology, Ludwig-Maximilians-Universitaet, Menzinger Strasse 67, D-80638 Muenchen, Germany

Submitted January 14, 2006; Accepted July 3, 2006;

Electronically published October 18, 2006

Online enhancement: appendix.

AвSTRACT: The contribution of nonecological factors to global patterns in diversity is evident when species richness differs between regions with similar habitats and geographic area. Mangrove environments in the Eastern Hemisphere harbor six times as many species of trees and shrubs as similar environments in the New World. Genetic divergence of mangrove lineages from terrestrial relatives, in combination with fossil evidence, suggests that mangrove diversity is limited by evolutionary transition into the stressful marine environment, the number of mangrove lineages has increased steadily over the Tertiary with little global extinction, and the diversity anomaly in mangrove vegetation reflects regional differences in the rate of origin of new mangrove lineages.

Keywords: mangrove, species diversity, diversity anomaly, adaptive shift, historical biogeography.

The idea that diversity is regulated locally by interactions among species dominated ecological thinking for decades following the integration of population biology into community ecology during the 1960s (MacArthur 1972; Kingsland 1985). Observed relationships between diversity and physical conditions of the environment (e.g., O'Brien et al. 2000; Hawkins et al. 2003) support this idea, although mechanisms linking diversity to local conditions have been

\footnotetext{
* Corresponding author; e-mail: ricklefs@umsl.edu.

† E-mail: andrea.schwarzbach@utb.edu.

₹ E-mail: renner@lrz.uni-muenchen.de.
}

Am. Nat. 2006. Vol. 168, pp. 805-810. (c) 2006 by The University of Chicago. 0003-0147/2006/16806-41556\$15.00. All rights reserved. elusive (Kleidon and Mooney 2000; Currie et al. 2004; Gillman and Wright 2006). Moreover, historical explanations based on evolutionary diversification over environmental gradients also predict an environment-diversity relationship (Latham and Ricklefs 1993; Wiens and Donoghue 2004; Ricklefs 2006). Accordingly, explanations for global patterns of diversity have increasingly drawn on large-scale processes set in the historical and geographic contexts of continental regions (Ricklefs 1987, 2004, 2005; Chown and Gaston 2000; Gaston and Blackburn 2000; Qian and Ricklefs 2000; Pennington et al. 2004; Hawkins et al. 2005, 2006). This shift was stimulated in part by the recognition of differences in diversity between apparently similar environments in different regions. Such diversity anomalies (Ricklefs and Latham 1993) suggested that large-scale processes influence species richness, whereas local determination of diversity would cause numbers of species to converge (Orians and Paine 1983; Schluter and Ricklefs 1993).

One of the most conspicuous global diversity anomalies contrasts species richness of mangrove trees and shrubs at both regional and local scales (Saenger et al. 1983; Tomlinson 1986; Duke 1992; Ellison et al. 1999) in the IndoWest Pacific region (IWP; $\geq 48$ species in 22 genera) and the Atlantic-Caribbean-East Pacific region (ACEP; eight or more species in five genera), despite similar areas (Saenger et al. 1983; Ellison et al. 1999) and essentially identical physical conditions of the mangrove environments (Chapman 1976; Duke 1992). Mangroves comprise about 57 species of trees and shrubs that belong to about 21 independent species-to-family-level mangrove lineages (Tomlinson 1986; Duke 1992). The approximately eight species of New World mangrove plants belong to four cosmopolitan (Rhizophora, Avicennia, Laguncularia) or formerly cosmopolitan (Pelliciera) genera, plus Conocarpus. In contrast, the Old World has 16 endemic genera (see appendix in the online edition of the American Naturalist for details). Here we describe the historical genesis of the contemporary mangrove flora by estimating the relative times of divergence of mangrove lineages from their closest terrestrial relatives. We used chloroplast $r b c L$ sequences to place 17 clades, comprising most of the 
world's mangrove species, in phylogenetic contexts. If the rate of nucleotide substitution were homogeneous over time and over lineages, the genetic distance between mangrove lineages and their closest nonmangrove relatives would represent the relative age of the last common ancestor of each pair, and it would therefore constrain the timing of the adaptive shift of one member of the pair into the mangrove habitat from adjacent terrestrial or freshwater environments.

\section{Phylogenetic Reconstruction and Genetic Distance}

All phylogenetic reconstructions are based on chloroplast (cpDNA) ribulose bisphosphate carboxylase large subunit $(r b c L)$ sequences downloaded from GenBank (for taxa and accession numbers, see table A1). Each mangrove taxon was grouped with available nonmangrove species in the same or closely related families to restrict the number of taxa in each analysis. Phylogenetic trees were produced using MrBayes, version 3.0 (Huelsenbeck and Ronquist 2001), with a general time-reversible model of nucleotide substitution ( $n s t=6$, gamma rate, and proportion invariant sites). For each analysis, MrBayes was iterated through 1,200,000 generations and sampled every 100 generations, with a burn-in period of 2,000 trees $(200,000$ generations). Thus, estimates of parameters were based on 10,000 trees sampled from generations 200,100 to $1,200,000$. Nexus files produced by MrBayes and estimated parameters for the evolutionary models were taken into PAUP*, version 4.0b10 (Swofford 1998), to obtain matrices of genetic distances among the species.

\section{Sources of Other Data}

Additional information on phylogenetic relationships of mangrove taxa from different DNA sequences was obtained from the literature, as explained in "Details of the Phylogenetic Analyses for Each Mangrove Clade" in the appendix. Ecological distributions of mangrove taxa are from Tomlinson (1986), Hutchings and Saenger (1987), and Duke (1992), and geographic distributions of nonmangrove taxa are from Mabberley (1987; see table A2). All statistical analyses were performed with the Statistical Analysis System (SAS, Cary, NC), using the CORR, GLM, NLIN, NPAR1WAY, and FACTOR procedures.

\section{Results and Discussion}

Buildup of the Mangrove Flora

Genetic distances (proportion of nucleotide substitutions) ranged from 0.0016 to 0.0708 . Distance increased with the taxonomic rank of mangrove clades (i.e., whether man- grove clades are single species, several species in a genus, or several genera in a tribe or family; Kruskal-Wallis $\chi^{2}=11.6, \mathrm{df}=2, P=.003$; see "Relationship of Genetic Distance to Level of Endemism" in the appendix). The genetic distance of each mangrove lineage to its nearest nonmangrove relative was positively related to the oldest occurrence of the mangrove taxon in the fossil record (Spearman rank-order correlation, $r_{\mathrm{s}}=0.63, P=.008$, $N=16$; slope of relationship $=0.00054 \pm 0.00016 \mathrm{SE}$ per million years (excluding Nypa because of the slow rate of $r b c L$ evolution in palms; Gaut et al. 1992; see "Relationship of Genetic Distance to Earliest Fossil Date" in the appendix). When four lineages without fossil records (age $=0$ ) were deleted, the trend of increasing genetic distance with earlier fossil appearance was only marginally significant $\left(r_{\mathrm{s}}=0.50, P=.096, N=12\right)$. Nonetheless, the relationships of genetic distance to clade rank and earliest fossil occurrence suggest that genetic distance might provide an approximate, albeit imperfect, estimate of time.

The historical pattern of entry of the contemporary mangrove lineages into the mangrove habitat can be visualized in a plot of the cumulative number of lineages as a function of genetic distance or date of first appearance in the fossil record (fig. 1). The first relationship is concave upwards, which could be caused by an increase in the rate of evolution of new mangrove lineages, extinction of older lineages (Nee et al. 1992; Harvey et al. 1994), or overestimation of genetic distance at older age (Rodriguez-Trelles et al. 2002). If new lineages entered the mangrove environment at a constant rate $c$ and existing lineages went extinct at a constant rate $d$ per lineage, the number of extant lineages after period $T$ ending in the present would be

$$
N=\frac{c}{d} \exp (d T)
$$

where $T$ is expressed in negative units of genetic distance. A nonlinear fit of equation (1) to the data in figure $1 a$ yielded estimates of $c=679 \pm 71 \mathrm{SE}$ and $d=38.3 \pm$ 2.7 SE $(F=762$, df $=2,14, P<.0001)$. The linear relationship of genetic distance to first fossil appearance, fitted with a zero intercept, was 0.00073 per million years $\left(F=42\right.$, df $=1,11, P<.0001, R^{2}=0.795 ;$ Nypa excluded; see "Relationship of Genetic Distance to Earliest Fossil Date" in the appendix). Accordingly, we can estimate $c=679 \times 0.00073=0.496$ per million years and $d=0.028$ per million years. The expected life span of a mangrove lineage, including all its descendants, would be $1 / d=35.8 \times 10^{6}$ years. An equilibrium number of lineages would be reached when $c=d N$ or $N=$ $0.496 / 0.028=17.7$, close to the contemporary number. 


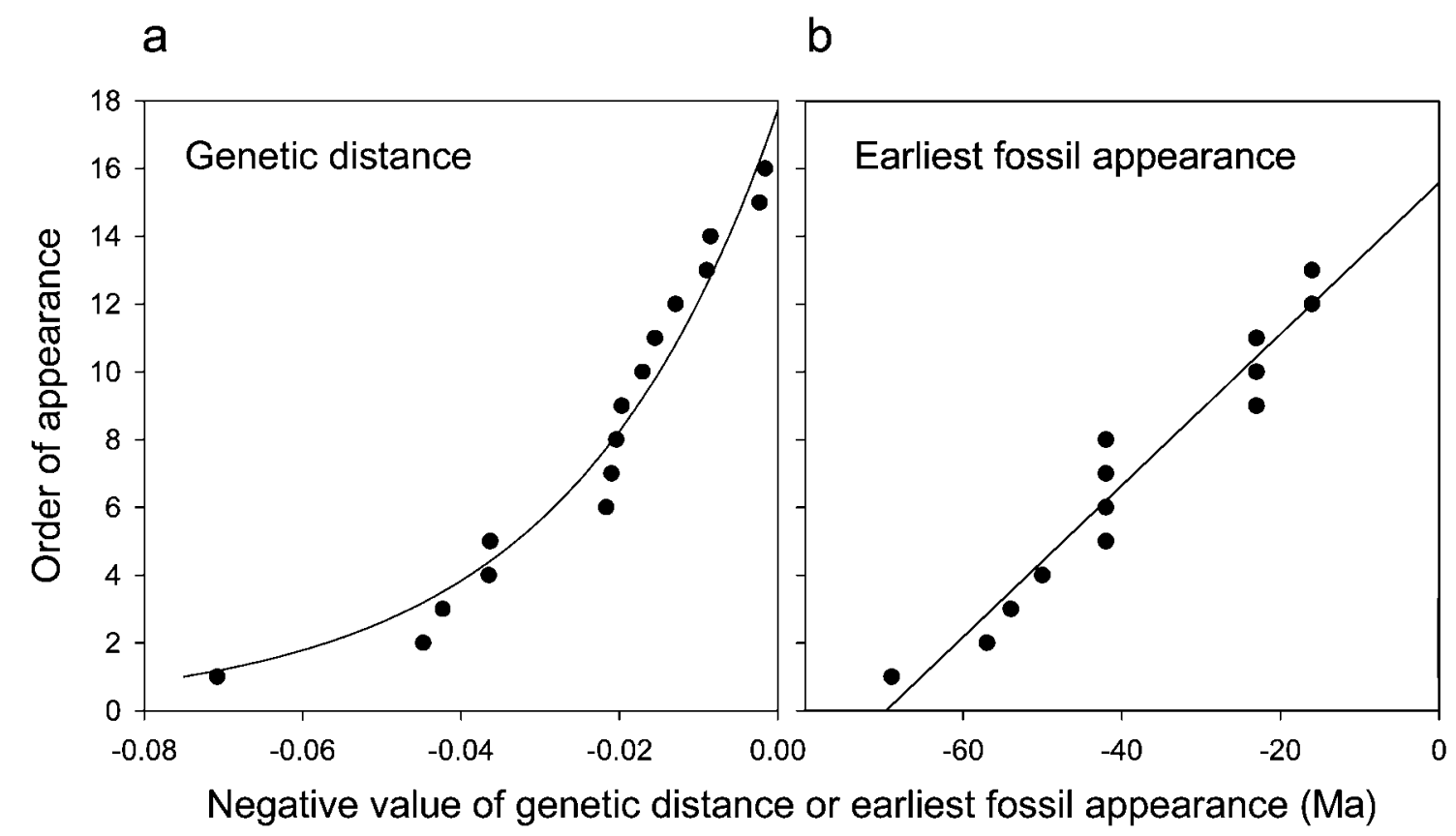

Figure 1: $a$, Increase in number of contemporary mangrove lineages as a function of genetic distance to the closest nonmangrove taxon. The vertical axis arrays the lineages from the most divergent or oldest (rank 1) to the least divergent ( $a$, rank 16) or youngest $(b$, rank 12). Thus, the order of appearance determines the cumulative number of lineages present at a particular time. See text for estimates of parameters of equation (1) fitted to the data. When data for Nypa are included in the analysis, the estimated parameters change little: $c=751 \pm 89, d=39.3 \pm 3.1(F=603$, $\mathrm{df}=2,15, P<.0001)$; excluding the largest genetic distance as a possible outlier also has no effect on the curvature of the relationship $(c=$ $718.7 \pm 89.3, d=42.6 \pm 3.6) . b$, Number of living mangrove lineages as a function of their earliest fossil appearances (Nypa included). The rate of increase is approximately linear at $0.224 \pm 0.017 \mathrm{SE}$ lineages per million years $\left(F=175 \mathrm{df}=1,11, P<.0001, R^{2}=0.94\right)$. When four lineages with fossil ages of 0 are added, the slope of the regression is virtually unchanged $(b=0.222 \pm 0.011)$.

Therefore, whether the number of mangrove lineages is close to equilibrium depends on whether $d$ estimates the true frequency of extinction or reflects an apparent change in the rate of formation of new lineages.

\section{Persistence of Mangrove Lineages}

Mangrove lineages increase in number as a linear function of earliest fossil appearance at about 0.224 per million years (fig. 1b). Adding eight lineages without fossils (fossil age $=0)$ to the 13 clades that have fossil records would increase the rate to approximately 0.36 lineages per million years, or almost three-quarters of the level obtained from the colonization-extinction model in equation (1). The fossil appearance data suggest that mangrove lineages have accumulated at a constant rate, implying that extinction is close to nil and that the increasing diversity of the mangrove flora during the Tertiary has not interfered with adaptive shifts of new lineages into the mangrove environment.

Paucity of global extinction is further supported by the following argument. The colonization rate estimated from the fit to the data in fig. $1 a\left(c=0.496 \mathrm{Ma}^{-1}\right)$ suggests that about 32 lineages $(0.496 \times 65 \mathrm{Ma})$ would have colonized the mangrove environment during the Tertiary. Accordingly, to produce the 21 extant lineages, 11 (34\%) would have disappeared globally. It is unlikely that so many extinct lineages would have left no trace because sediments of mangrove and near-shore marine environments are conducive to tissue preservation (Muller 1981; Graham 1995). Global extinction of mangrove taxa based on fossils has been recognized in the case of Paleowetherellia and Wetherellia from the Upper Cretaceous of Egypt and the Lower Eocene of London, Virginia, and Germany, respectively, which probably represent the same mangrove lineage (Mazer and Tiffney 1982). Pollen of the extinct presumed mangrove Brevitricolpites variabilis was present in the Caribbean region during the Eocene (Graham 1995). Two other cases of regional extirpation based on fossil data are the disappearance of the palm Nypa from New World mangroves after the middle of the Eocene and of Pelliciera from Western Europe and elsewhere in the Old World after the Lower Eocene (Saenger 1998; Ellison et al. 1999). Thus, although lineages might undergo local extirpation and re- 
colonization (Schwarzbach and Ricklefs 2000), the fossil record at the coarser regional and global scales does not suggest substantial turnover of mangrove lineages themselves.

Infrequent lineage extinction fits with the steady increase of mangrove diversity throughout the Tertiary. Whether, in addition, the rate of accumulation of new lineages has increased, as suggested by the relationship of lineages to genetic distance, cannot be decided from the present data because of possible overestimation of genetic distance at older ages (Rodriguez-Trelles et al. 2002).

\section{Diversification within the Mangrove Flora}

Several lineages have undergone diversification within the mangrove environment. The most species-rich is the endemic mangrove tribe Rhizophoreae, which includes four genera (Rhizophora, Bruguiera, Ceriops, and Kandelia) and about 17 species; it is also one of the oldest lineages in the fossil record, after the monotypic Nypa, and probably is contemporaneous with Sonneratia. In addition, the Rhizophoreae contains the earliest ancestral node (crown group age) of any mangrove clade. When species proliferate at a constant rate according to a pure speciation model, the logarithm of the number of species is linearly related to age with a slope $(s)$ equal to the exponential rate of increase. In the sample of mangroves included in this analysis, $s=27.9 \pm 9.7$ SE per unit genetic distance $\left(F=8.2, \mathrm{df}=1,15, P=.012, R^{2}=0.35\right.$; see "Relationship of Number of Species to the Genetic Distance of a Mangrove Lineage"), which is approximately 0.020 per million years and an average waiting time to branching events (speciation) within mangrove taxa of $50 \mathrm{Ma}$. If mangrove taxa also suffered extinction, the estimated branching rate would be correspondingly higher (Harvey et al. 1994). Regardless, the Rhizophoreae clearly have diversified more rapidly than the average mangrove clade. When the natural logarithm of species number was regressed against earliest fossil date, the slope was also $0.020 \pm 0.005$ per million years (no intercept; $F=14.1$, df $=1,15, P=.0017, R^{2}=0.47$ ), or about one-quarter of the net diversification rate for angiosperms as a whole (Magallón and Sanderson 2001).

\section{Origin of the Mangrove Diversity Anomaly}

Because global extinction of mangrove lineages appears to be relatively infrequent, the greater diversity of clades in the IWP region compared with the ACEP region likely can be attributed to a greater rate of origin of mangrove lineages in the IWP region. Area of origin cannot be identified with certainty, but earliest fossils and distributions of contemporary nonmangrove relatives provide a basis for in- ference. The three currently cosmopolitan lineages of mangroves (Rhizophoreae, Avicennia, and Lumnitzera/Laguncularia) are relatively old (genetic divergence $>0.04$, fossil ages 50, 42, and $23 \mathrm{Ma}$, respectively), and early fossils come from Europe and the IWP region. The earliest fossils of the New World Pelliciera are also from southern Europe, indicating a Tethyan origin for these lineages with subsequent spread to the New World (Saenger 1998; Ellison et al. 1999). All fossil occurrences of mangrove lineages currently endemic to the Old World are restricted to the IWP region, except for the formerly cosmopolitan Nypa and fossil Kandelia from Alaska, north of its present occurrence in eastern Asia.

Also, the distributions of close relatives identified in our molecular phylogenetic analyses place the origins of mangrove lineages during the latter half of the Tertiary in the Old World in groups that are either cosmopolitan or are restricted to the Old World at present (table 1). Significantly, no mangrove lineage has a nonmangrove sister taxon restricted to the New World. Thus, lineage (and species) richness of IWP mangroves is primarily endemic-produced in the Old World and currently restricted to the Old World. The cosmopolitan mangrove lineages tend to be older, most likely dating from a period during which the Tethys Seaway was open and provided a tropical connection between the IWP and Atlantic Ocean as well as an environment suitable for the origin of mangrove lineages (Ricklefs and Latham 1993).

\section{Ecology and the Evolutionary Transition to the Mangrove Environment}

Insight into the origins of mangrove plants might be gained from the relationship between ecological position within the mangrove environment and lineage age, assuming that the younger mangrove lineages represent earlier stages of adaptation to salt and/or oxygen stress. Most mangrove plant species have been characterized (Duke 1992) according to position within an estuary (upriver [freshwater] $=3$, midriver [brackish] $=2$, downriver [saline] $=1$ ) and height in the intertidal zone (high [rarely inundated] $=3$, mid $=2$, low [frequently inundated, most anoxic] $=1$ ), indicating the relative satura-

Table 1: Location of nonmangrove sister taxa of 17 mangrove lineages according to the age of fossil mangroves or the genetic distance between them

\begin{tabular}{lcccccccc}
\hline $\begin{array}{l}\text { Location of } \\
\text { sister }\end{array}$ & \multicolumn{2}{c}{ Earliest fossils } & & \multicolumn{4}{c}{ Genetic distance $(D)$} \\
\cline { 2 - 3 } \cline { 7 - 9 } & $>30 \mathrm{Ma}$ & $<30 \mathrm{Ma}$ & & $>.03$ & $.02-.03$ & $.01-.02$ & $<.01$ \\
\hline New World & 0 & 0 & & 0 & 0 & 0 & 0 \\
Old World & 4 & 8 & & 3 & 1 & 4 & 4 \\
Cosmopolitan & 3 & 2 & & 2 & 2 & 1 & 0 \\
\hline
\end{tabular}


tion of the sediment by water. Lineages that appear earlier in the fossil record tend to extend farther down into the intertidal zone (minimum height: $r=-0.52, P=.027$, $n=16$; mean height: $r=-0.49, P=.055, n=16$ ). These trends are similarly negative, but not significant, for genetic distance $(r=-0.41, P=.11, n=16)$. We applied a factor analysis to 16 lineages for which data were available for earliest fossil record, middle and most saline positions in estuaries, and middle and most anoxic positions in the intertidal zone (see "Factor Analysis of Earliest Fossil Date, Depth in the Intertidal Zone, and Position in Estuary for 16 Mangrove Lineages" in the appendix). Two factors explained $87 \%$ of the total variance, with approximately equal loadings. The first incorporated earliest fossil age and extension to lower levels of the intertidal zone, whereas the second factor described position within estuaries without regard to age or height in the intertidal zone. This is consistent with the principal barrier to invasion of the mangrove environment being inundation of the roots and tolerance of anoxia under the influence of saltwater. Plant lineages appear to enter the mangrove environment directly from terrestrial systems, in some cases through dry, saline, back-mangrove habitats (Tomlinson 1986), rather than by way of swamp forests or river margins.

The diversity anomaly in mangrove species richness between the New World and the Old World primarily reflects a difference in the origin of new mangrove lineages from terrestrial nonmangrove taxa. We believe that local eco. logical conditions have had little influence on mangrove lineage origin (although they may have determined local extinctions) because of (1) the magnitude of the diversity anomaly, (2) the globally overriding influence of high salinity and sediment anoxia in the physical environment (Chapman 1976; Saenger et al. 1983), and (3) the pantropical distribution of several of the oldest mangrove lin. eages interspersed ecologically with additional endemic lineages in the IWP region (Tomlinson 1986; Duke 1992). As an alternative mechanism to differential mangrove origins, more New World lineages could have existed but become extinct at a higher rate. If this were true, however, these lineages would represent ACEP endemics, fossils of which cannot be related to extant Old World mangroves Plausibly, the high mangrove diversity in the IWP region has resulted from the continuous presence of large areas of continental shelf with islands scattered among shallon tropical seas, initially along the Tethyan border, including parts of contemporary Europe, and currently in the regiori of the Sunda Shelf of Malaysia and Indonesia. A setting of small islands in a shallow sea would isolate populations of incipient mangrove lineages in areas dominated by mangrove environment, favoring local adaptation uninhibited by gene flow from primarily terrestrial populations. Severa terrestrial plants, such as Hibiscus tiliaceus (Malvaceae), Cynometra ramiflora (Fabaceae), and Ardisia elliptica (Myrsinaceae), extend their distributions into back-mangrove environments (Tomlinson 1986), suggesting a predisposition to become adapted to salt-influenced habitats and perhaps representing the initial stages of formation of new mangrove lineages. Two-thirds of 48 such species listed by Tomlinson (1986) occur in the Indo-Pacific region. The role of geographic isolation in the formation of populations with further adaptation to the mangrove environment remains to be tested. Clearly, however, the mangrove diversity anomaly reflects primarily historic and geographic factors rather than ecological constraints, and global mangrove diversity continues to increase at a rate that has been undiminished through the Tertiary.

\section{Acknowledgments}

This work was supported in part by a grant from the University of Missouri Research Board. We are grateful for constructive comments of B. Hawkins and an anonymous reviewer.

\section{Literature Cited}

Chapman, V. J. 1976. Mangrove vegetation. J. Cramer, Vaduz.

Chown, S. L., and K. J. Gaston. 2000. Areas, cradles and museums: the latitudinal gradient in species richness. Trends in Ecology \& Evolution 15:311-315.

Currie, D. J., G. G. Mittelbach, H. V. Cornell, R. Field, J. F. Guegan, B. A. Hawkins, D. M. Kaufman, et al. 2004. Predictions and tests of climate-based hypotheses of broad-scale variation in taxonomic richness. Ecology Letters 7:1121-1134.

Duke, N. C. 1992. Mangrove floristics and biogeography. Pages 63100 in A. I. Robertson and D. M. Alongi, eds. Tropical mangrove ecosystems. Vol. 41. Coastal and estuarine studies. American Geophysical Union, Washington, DC.

Ellison, A. M., E. J. Farnsworth, and R. E. Merkt. 1999. Origins of mangrove ecosystems and the mangrove biodiversity anomaly. Global Ecology and Biogeography Letters 8:95-115.

Gaston, K. J., and T. M. Blackburn. 2000. Pattern and process in macroecology. Blackwell Science, Oxford.

Gaut, B. S., S. V. Muse, W. D. Clark, and M. T. Clegg. 1992. Relative rates of nucleotide substitution at the $r b c L$ locus of monocotyledonous plants. Journal of Molecular Evolution 35:292-303.

Gillman, L. N., and S. D. Wright. 2006. The influence of productivity on the species richness of plants: a critical assessment. Ecology 87: 1234-1243.

$\rightarrow$ Graham, A. 1995. Diversification of Gulf/Caribbean mangrove communities through Cenozoic time. Biotropica 27:20-27.

Harvey, P. H., R. M. May, and S. Nee. 1994. Phylogenies without fossils. Evolution 48:523-529.

Hawkins, B. A., R. Field, H. V. Cornell, D. J. Currie, J. F. Guegan, D. M. Kaufman, J. T. Kerr, et al. 2003. Energy, water, and broadscale geographic patterns of species richness. Ecology 84:31053117.

Hawkins, B. A., J. A. F. Diniz-Filho, and S. A. Soeller. 2005. Water 
links the historical and contemporary components of the Australian bird diversity gradient. Journal of Biogeography 32:1035-1042.

$\rightarrow$ Hawkins, B. A., J. A. F. Diniz-Filho, C. A. Jaramillo, and S. A. Soeller 2006. Post-Eocene climate change, niche conservatism, and the latitudinal diversity gradient of New World birds. Journal of Bio geography 33:770-780.

$\rightarrow$ Huelsenbeck, J. P., and F. Ronquist. 2001. MrBayes: Bayesian inference of phylogenetic trees. Bioinformatics 17:754-755.

Hutchings, P., and P. Saenger. 1987. Ecology of mangroves. University of Queensland Press, St. Lucia, Australia.

Kingsland, S. E. 1985. Modeling nature: episodes in the history of population ecology. University of Chicago Press, Chicago.

$\rightarrow$ Kleidon, A., and H. A. Mooney. 2000. A global distribution of biodiversity inferred from climatic constraints: results from a processbased modelling study. Global Change Biology 6:507-523.

$\rightarrow$ Latham, R. E., and R. E. Ricklefs. 1993. Global patterns of tree species richness in moist forests: energy-diversity theory does not accoun for variation in species richness. Oikos 67:325-333.

Mabberley, D. J. 1987. The plant book. Cambridge University Press, Cambridge.

MacArthur, R. H. 1972. Geographical ecology: patterns in the distribution of species. Harper \& Row, New York.

$\rightarrow$ Magallón, S., and M. J. Sanderson. 2001. Absolute diversification rates in angiosperm clades. Evolution 55:1762-1780.

$\rightarrow$ Mazer, S. J., and B. H. Tiffney. 1982. Fruits of Wetherellia and Paleowetherellia (Euphorbiaceae) from Eocene sediments in Virginia and Maryland. Brittonia 34:300-333.

$\rightarrow$ Muller, J. 1981. Fossil pollen records of extant angiosperms. Botanical Review 47:1-142.

$\rightarrow$ Nee, S., A. O. Mooers, and P. H. Harvey. 1992. Tempo and mode or evolution revealed from molecular phylogenies. Proceedings of the National Academy of Sciences of the USA 89:8322-8326.

O'Brien, E. M., R. Field, and R. J. Whittaker. 2000. Climatic gradients in woody plant (tree and shrub) diversity: water-energy dynamics, residual variation, and topography. Oikos 89:588-600.

Orians, G. H., and R. T. Paine. 1983. Convergent evolution at the community level. Pages 431-458 in D. J. Futuyma and M. Slatkin, eds. Coevolution. Sinauer, Sunderland, MA.

$\rightarrow$ Pennington, R. T., Q. C. B. Cronk, and J. A. Richardson. 2004. Introduction and synthesis: plant phylogeny and the origin of major biomes. Philosophical Transactions of the Royal Society B: Biological Sciences 359:1455-1464.

$\rightarrow$ Qian, H., and R. E. Ricklefs. 2000. Large-scale processes and the
Asian bias in species diversity of temperate plants. Nature 407: 180-182.

Ricklefs, R. E. 1987. Community diversity: relative roles of local and regional processes. Science 235:167-171.

2004. A comprehensive framework for global patterns in biodiversity. Ecology Letters 7:1-15.

. 2005. Phylogenetic perspectives on patterns of regional and local species richness. Pages 16-40 in E. Bermingham, C. Dick, and C. Moritz, eds. Tropical rainforests: past, present, and future. University of Chicago Press, Chicago.

- 2006. Evolutionary diversification and the origin of the diversity/environment relationship. Ecology 87(suppl.):3-13.

Ricklefs, R. E., and R. E. Latham. 1993. Global patterns of diversity in mangrove floras. Pages 215-229 in R. E. Ricklefs and D. Schluter, eds. Species diversity in ecological communities: historical and geographical perspectives. University of Chicago Press, Chicago.

$\rightarrow$ Rodriguez-Trelles, F., R. Tarrio, and F. J. Ayala. 2002. A methodological bias toward overestimation of molecular evolutionary time scales. Proceedings of the National Academy of Sciences of the USA 99:8112-8115.

$\rightarrow$ Saenger, P. 1998. Mangrove vegetation: an evolutionary perspective. Marine and Freshwater Research 49:277-286.

Saenger, P., E. J. Hegerl, and J. D. S. Davie. 1983. Global status of mangrove ecosystems. Environmentalist 3:1-88.

Schluter, D., and R. E. Ricklefs. 1993. Convergence and the regional component of species diversity. Pages 230-242 in R. E. Ricklefs and D. Schluter, eds. Species diversity in ecological communities: historical and geographical perspectives. University of Chicago Press, Chicago.

Schwarzbach, A. E., and R. E. Ricklefs. 2000. Systematic affinities of Rhizophoraceae and Anisophylleaceae, and intergeneric relationships within Rhizophoraceae, based on chloroplast DNA, nuclear ribosomal DNA, and morphology. American Journal of Botany 87:547-564.

Swofford, D. L. 1998. PAUP*: phylogenetic analyses using parsimony ( ${ }^{*}$ and other methods). Version 4.0b10. Sinauer, Sunderland, MA.

Tomlinson, P. B. 1986. The botany of mangroves. Cambridge University Press, Cambridge.

$\rightarrow$ Wiens, J. J., and M. J. Donoghue. 2004. Historical biogeography, ecology and species richness. Trends in Ecology \& Evolution 19: 639-644.

Associate Editor: Steven L. Chown Editor: Michael C. Whitlock 